\title{
Psicologia Escolar na concepção de professores de Educação Infantil e Ensino Fundamental
}

\author{
Caroline Benezath Rodrigues Bastos \\ Universidade Federal do Espírito Santo - Vitória - ES - Brasil \\ Simone Chabudee PyIro \\ Universidade Vila Velha - Vila Velha - ES - Brasil
}

\begin{abstract}
Resumo
O objetivo desta pesquisa foi verificar o papel da Psicologia Escolar de acordo com a concepção de professores de um Centro Municipal de Educação Infantil (CMEI) e de uma Escola Municipal de Ensino Fundamental (EMEF), ambos localizados na cidade de Vitória (ES). Foram realizadas entrevistas individuais com 49 professores e um estagiário, sendo 26 do CMEI e 24 da EMEF. Os dados foram analisados qualitativamente através da análise de conteúdo. Verificou-se que para os entrevistados a atuação do psicólogo escolar deve estar voltada principalmente para o aluno "problema" e sua família. Entretanto, a perspectiva crítica e contextualizada da Psicologia Escolar enfatiza que o psicólogo escolar deve intervir de forma ampla com todos os envolvidos no processo de desenvolvimento e de ensino e aprendizagem do aluno, incluindo a própria escola, os profissionais e toda a comunidade.
\end{abstract}

Palavras-chave: Psicologia Escolar; psicólogo escolar; atuação do psicólogo.

\section{School Psychology in the design of Early Childhood Education and Elementary School teachers}

\begin{abstract}
The objective of this research was to investigate the role of School Psychology according to the conception of teachers of a Municipal Center for Early Childhood Education (CMEI) and a Municipal Elementary School (EMEF), both located in the city of Vitória (ES). Individual interviews were held with 49 teachers and a trainee, 26 of CMEI and 24 EMEF. The data were analyzed qualitatively through content analysis. It was found that for the respondents the performance of the school psychologist should be mainly focused on the student "problem" and his family. However, critical and contextualized perspective of School Psychology emphasizes that the school psychologist should intervene broadly with all stakeholders in the development process and teaching and student learning, including the school itself, professionals and the community.
\end{abstract}

Keywords: School psychology; school psychologist; psychologist performance.

\section{Psicología Escolar en la concepción de profesores de Educación Infantil y Enseñanza Primaria}

\section{Resumen}

El objetivo de esta investigación fue verificar el papel de la Psicología Escolar de acuerdo con la concepción de profesores de un Centro Municipal de Educación Infantil (CMEI) y de una Escuela Municipal de Enseñanza Primaria (EMEF), ambos localizados en la ciudad de Vitória (ES). Se realizaron entrevistas individuales a 49 profesores y un profesor en formación, siendo 26 del CMEI y 24 de la EMEF. Se analizaron los datos cualitativamente por intermedio del análisis de contenido. Se verificó que para los encuestados la actuación del psicólogo escolar debe estar volcada principalmente para el alumno "problema" y su familia. Sin embargo, la perspectiva crítica y contextualizada de la Psicología Escolar enfatiza que el psicólogo escolar debe intervenir de forma amplia con todos los implicados en el proceso de desarrollo y de enseñanza y aprendizaje del alumno, incluyendo la propia escuela, los profesionales y toda la comunidad.

Palabras clave: Psicología Escolar; psicólogo escolar; actuación del psicólogo. 


\section{Introdução}

Sabe-se que a Psicologia Escolar "é uma área de produção de conhecimentos, pesquisa e intervenção de psicólogos que atuam em estreita relação com o campo educativo" (Carvalho \& Marinho-Araújo, 2010, p.220). Dessa forma, a Psicologia Escolar vincula a Psicologia à Educação (Wechsler, 2001), de modo que o psicólogo colabore amplamente na reflexão e na orientação dos processos de desenvolvimento e ensino-aprendizagem (Piletti, 2003; Vebber, 2013), visando compreender, a partir de pesquisas e da atuação profissional em Psicologia, os processos de interações do contexto educacional (Souza, 2009; Vebber, 2013).

Historicamente, a Psicologia Escolar era considerada uma área distinta da Psicologia Educacional, sendo a primeira vinculada à prática e a última, à pesquisa (Souza, 2009). Entretanto, "essa dicotomia passou a ser questionada por uma perspectiva crítica que considerava que teoria e prática são elementos indissociáveis na constituição de uma ciência dita humana" (Souza, 2009, p. 179). Portanto, seguindo essa concepção crítica e atual, ambos os termos serão considerados como sinônimos neste artigo.

Sendo assim, Meira (2003) enfatiza que o objeto de estudo e intervenção da Psicologia Escolar é a compreensão das relações que ocorrem no encontro entre o sujeito e a educação, e sua função é contribuir para um processo educacional qualitativamente superior, favorecendo a socialização do saber, humanização e o pensamento crítico.

Sabe-se que esta abordagem crítica da Psicologia Escolar intensificou-se no Brasil (Souza, 2009), apontando também novas formas de conceber os problemas advindos do contexto educacional. Frente a isso, a literatura evidencia que houve um redirecionamento de uma perspectiva tradicional, voltada para o "aluno-problema", para uma perspectiva crítica, que rompe com a culpabilização dos alunos pelas dificuldades escolares, trazendo um enfoque sistêmico, no qual considera a interação de todos os atores abarcados no processo educacional (Miranda, Lima, Teixeira, Chaves, \& Barros, 2007; Souza, 2009).

Dessa forma, a função do psicólogo na escola é agir nos processos subjetivos em favor da conscientização dos envolvidos na educação, e esta intervenção deve englobar os alunos, os profissionais da instituição, a família e todos os outros participantes da dinâmica escolar (Carvalho \& Marinho-Araujo, 2009). É preciso estabelecer atuações conectadas com os pais, com os professores, com a direção da escola, e com outros especialistas, objetivando o aperfeiçoamento do processo educacional como um todo, pois a criança se constitui socialmente (Vebber, 2013).

Patto (1997) já ressaltava o quanto é fundamental essa superação do psicologismo reducionista, que é repleto de mito e pouco elucidativo. Por isso, é necessário redirecionar a ênfase da atuação do psicólogo escolar para todo o processo educativo, incluindo as relações interpessoais que acontecem na escola (Souza, 2009). É preciso, então, refletir sobre a complexidade de práticas que estabelecem a história escolar cotidiana (Machado \& Souza, 2004), consi- derando vários aspectos de um mesmo fenômeno (Andrada, 2005).

Em relação a isso, Vokoy e Pedroza (2005) enfatizam que "o modelo de atuação do psicólogo deve ser fundamentado no paradigma interdisciplinar, contextual e crítico" (p.95), intervindo, de forma ampla, com todos os componentes do processo de desenvolvimento e de ensino e aprendizagem (Andrada, 2005).

Carvalho e Marinho-Araújo (2010) destacam, nessa perspectiva crítica, que a Psicologia Escolar concebe o psicólogo que atua neste contexto, como um profissional que visa a reflexão, transformação e "ressignificação de saberes e fazeres dos educadores" (p.220). Assim, ao invés de focar sua atenção nos atendimentos individuais de alunos, o psicólogo escolar deve buscar compreender as intrínsecas interações escolares (Carvalho \& Marinho-Araujo, 2009; Giongo \& Oliveira-Menegotto, 2010), possuindo uma visão institucional e sistêmica (Giongo \& Oliveira-Menegotto, 2010).

Para intervir dessa forma, o psicólogo escolar também deve considerar todos os aspectos do desenvolvimento da criança, percebendo-a de forma integral (Giongo \& Oliveira-Menegotto, 2010; Vokoy \& Pedroza, 2005), contemplando o desenvolvimento afetivo, cognitivo e social de forma interligada, assim como propõem Piaget e Inhelder (1994). É necessário, então, compreender que os aspectos do desenvolvimento infantil influenciam-se entre si, de modo que o desenvolvimento cognitivo influencia o desenvolvimento social da criança e vice-versa, já que ambos se desenvolvem paralelamente e de forma interdependente (Barros, 2002). Portanto, há uma perspectiva ampliada do processo educativo, em que o aluno é compreendido dentro de emaranhadas relações (Carvalho \& Marinho-Araujo, 2009).

Logo, observa-se que, segundo a revisão de literatura, a Psicologia Escolar deve se basear nas perspectivas institucional, sistêmica e crítica. Na perspectiva institucional, o psicólogo escolar trabalha nas relações que ocorrem na escola juntamente com a família e toda a comunidade (Giongo \& Oliveira-Menegotto, 2010). Para a perspectiva sistêmica, a Psicologia Escolar deve considerar todos os elementos que influenciam o desenvolvimento do educando, incluindo aspectos: cognitivos, sociais, escolares, entre outros (Giongo \& Oliveira-Menegotto, 2010). A perspectiva crítica analisa de forma aprofundada as múltiplas determinações do fenômeno educacional, de forma a compreendê-lo em seu caráter histórico e social (Meira, 2003). Portanto, ressalta-se que essas perspectivas possuem diferentes epistemologias, mas entram em consenso ao permitir que compreendamos que o psicólogo escolar deve intervir de forma ampla com todos os envolvidos no processo de desenvolvimento e de ensino e aprendizagem do aluno, rompendo com o foco na criança "problema" e em sua família, como ocorre no modelo clínico tradicional de atuação (Meira, 2003).

Em suma, Rossetti, Silva, Batista, Stein, e Hulle (2004) afirmam que a Psicologia Escolar pode atuar "no trabalho com toda a instituição escolar, na discussão e a reformulação dos processos de avaliação, na proposta de novas 
metodologias de ensino, na prevenção, avaliação e intervenção no que diz respeito às dificuldades de aprendizagem, entre muitas outras" (p.194). De acordo com a Resolução n 013/2007 do Conselho Federal de Psicologia (2007), dentre as diversas possibilidades de atuação do psicólogo especialista em Psicologia Escolar/Educacional, pode-se elencar:

a) aplicar conhecimentos psicológicos na escola, concernentes ao processo ensino-aprendizagem, em análises e intervenções psicopedagógicas; referentes ao desenvolvimento humano, às relações interpessoais e à integração família-comunidade-escola, para promover o desenvolvimento integral do ser; b) analisar as relações entre os diversos segmentos do sistema de ensino e sua repercussão no processo de ensino para auxiliar na elaboração de procedimentos educacionais capazes de atender às necessidades individuais (p.18).

Diante disso, podemos refletir o quanto a presença do psicólogo torna-se relevante no contexto escolar. Entretanto, a Psicologia Escolar parece não estar presente na rotina da grande maioria das escolas da cidade de Vitória (ES), uma vez que se observa um reduzido número de profissionais da área de Psicologia atuando diretamente dentro das escolas deste município (Rossetti e cols., 2004). Este dado pode ser observado nos resultados da pesquisa de Rossetti e cols. (2004) que, através de um estudo exploratório, realizaram um panorama da Psicologia Escolar na cidade de Vitória (ES) e verificaram que os psicólogos escolares entrevistados não possuíam vínculo empregatício formal com as escolas em que atuavam e não trabalhavam nas escolas todos os dias da semana. Além disso, os autores ressaltaram que "no caso das escolas públicas, a inserção da psicologia escolar é praticamente inexistente" (Rossetti \& cols., 2004, p.192).

Em geral, a escassez de psicólogos atuando em escolas no município de Vitória (ES) não difere da realidade nacional e não é uma realidade recente, pois em sua pesquisa sobre o panorama nacional de formação e atuação do psicólogo escolar no século passado, Wechsler (1989) observou a diminuição da busca pela Psicologia Escolar, a eliminação de estágios nesta área em algumas universidades particulares e enfatizou que apenas $7 \%$ dos profissionais trabalhavam exclusivamente na escola. Para Rossetti e cols. (2004), a baixa inserção de profissionais na área pode estar ocorrendo devido a um desconhecimento das possíveis contribuições da Psicologia Escolar para a Educação.

Além disso, quando o psicólogo se insere na escola, encontra muitos obstáculos, tais como a expectativa de confirmação de que o problema está necessariamente no aluno ou em sua família (Andrada, 2005). Esta é uma concepção limitada, uma vez que desconsidera os diversos elementos envolvidos no processo educacional, como a própria escola, os profissionais da instituição e toda a comunidade (Nakamura, Lima, Tada, \& Junqueira, 2008).

Há, portanto, um desconhecimento e incompreensão por parte da escola acerca do papel e das principais atividades possíveis de serem desempenhadas pelo psicólogo escolar, de modo que este profissional ora é visto como aquele que vai solucionar rapidamente todos os conflitos existentes na escola; ora é visto como desnecessário, ou como perigoso para a instituição (Rossetti \& cols., 2004).

Contudo, essa visão limitada da Psicologia Escolar não é restrita aos profissionais que atuam nas escolas, se estende também para os próprios alunos. Sant'Ana, Euzébios Filho, Lacerda Junior, e Guzzo (2009) observaram nos resultados de sua pesquisa, que 240 alunos do ensino fundamental de uma escola pública municipal de Campinas (SP), apesar de possuírem uma visão positiva frente ao trabalho do psicólogo escolar, evidenciaram, por outro lado, uma concepção limitada sobre o seu papel, pois o concebem como um profissional que conversa sobre a vida, favorece as relações escolares e soluciona conflitos. Dessa forma, os estudantes entrevistados demonstraram carecer de informações delineadas sobre a função do psicólogo escolar, tornando fundamental a ampla divulgação da atuação deste profissional (Sant'Ana \& cols., 2009).

Portanto, sabe-se, por um lado, que a Psicologia Escolar possui um importante papel no processo educacional, de forma a atuar tanto com os alunos, com as famílias, com os profissionais e com toda a sociedade, considerando a história escolar, as condições em que se dão o processo de ensino e aprendizagem, as relações sociais construídas cotidianamente na escola (incluindo a relação professor-aluno), o currículo escolar, o projeto político pedagógico, a metodologia, os mecanismos institucionais e o próprio conceito de educação, entre tantos outros fatores. Porém, por outro lado, parece haver, por parte das escolas, um desconhecimento acerca do papel do psicólogo escolar. Diante disso, tornou-se relevante compreender como o papel da Psicologia Escolar e as atuações possíveis de serem desempenhadas pelo psicólogo escolar estão sendo vistos por professores de educação infantil e do ensino fundamental da cidade de Vitória (ES).

\section{Método}

\section{Tipo de Estudo}

A presente pesquisa ${ }^{1}$ foi do tipo descritiva segundo os objetivos; de levantamento quanto ao procedimento de coleta; de campo quanto às fontes de informação; e qualitativa segundo a natureza dos dados (Gonsalves, 2003).

\section{Participantes}

Participaram deste estudo 49 professores e um estagiário, sendo 26 de um Centro Municipal de Educação Infantil (CMEI) e 24 de uma Escola Municipal de Ensino Fun-

\footnotetext{
1 Esta pesquisa está em consonância com o estabelecido na Resolução $n^{\circ} 466$ de 12 de dezembro de 2012 do Conselho Nacional de Saúde (2012), que aprova as diretrizes e normas regulamentadoras de pesquisas envolvendo seres humanos; e com a Resolução $n^{\circ}$ 016/2000 de 20 de dezembro de 2000 do Conselho Federal de Psicologia (2000), que dispõe sobre a realização de pesquisa em Psicologia com seres humanos.
} 
damental (EMEF), ambos localizados na cidade de Vitória (ES). Do CMEI foram entrevistados: 12 professores e um estagiário do turno matutino, 11 do turno vespertino e dois que atuam em ambos os turnos. Da EMEF, participaram da pesquisa: nove professores do turno matutino, 12 do turno vespertino e três que atuam em ambos os turnos.

Os professores foram escolhidos como participantes da pesquisa, pois representam uma parcela importante da concepção que a escola possui a respeito do trabalho do psicólogo dentro da instituição, uma vez que, em geral, são os profissionais com maior representatividade numérica dentro das escolas e os que mantêm uma relação de maior proximidade com os alunos, coordenação e direção.

\section{Instrumento}

Os dados foram coletados por meio de um roteiro de entrevista que contemplou 10 questões semiestruturadas que abordaram a concepção dos professores sobre o papel do psicólogo escolar e suas possíveis atuações.

\section{Procedimentos de Coleta de Dados}

As entrevistas foram realizadas individualmente, nas próprias escolas, em horários acordados entre a entrevistadora e os participantes. Foram gravadas em áudio e posteriormente transcritas na íntegra para a análise dos dados.

Os dados da pesquisa só foram coletados após sua aprovação por um Comitê de Ética em Pesquisa, e após a assinatura do Termo de Consentimento Livre e Esclarecido pelos participantes.

\section{Procedimentos de Análise de Dados}

Os dados coletados foram analisados qualitativamente por meio da Análise de Conteúdo, segundo Bardin (2010).

\section{Resultados e Discussão}

\section{Caracterização dos participantes}

Dentre os 50 participantes deste estudo, os 25 professores e um estagiário que atuam na educação infantil trabalhavam com turmas do Grupo 1 ao Grupo 6, ou seja, com crianças que têm entre seis meses e seis anos de idade; e os 24 professores do ensino fundamental, atuavam com turmas do segundo ao nono ano, que abrangem crianças a partir de seis anos de idade. O tempo total de atuação dos professores nas escolas variou de 15 dias a 20 anos, havendo uma concentração de professores que trabalham nas escolas entre dois e cinco anos (44\%).
Considerando que foram entrevistados $76,9 \%$ dos professores das duas escolas, houve certa variação, como era de se esperar, quanto às disciplinas que estes ministram, de modo que $43,1 \%$ dos professores entrevistados trabalham com disciplinas específicas (Arte, Ciências, Educação Física, Geografia, História, Informática e Português) e disciplinas de Educação Especial e Reforço; 39,2\% são professores de Educação Infantil; e 17,7\% são professores de Núcleo Comum (disciplina que envolve Português, Matemática, História, Geografia e Ciências).

O ano de formação dos referidos professores variou de 1978 a 2009 , sendo que $46,4 \%$ se formaram entre os anos de 2000 e 2009 e 39,3\% entre os anos de 1990 e 1999. Do total de entrevistados, $86 \%$ possuem uma graduação e $12 \%$ possuem duas graduações, sendo $50 \%$ formados em Pedagogia. Além disso, $86 \%$ dos professores possuem especialização, divididos em $76,7 \%$ que possuem uma especialização e $23,3 \%$ que possuem duas ou três especializações.

Quase todos os entrevistados (96\%) realizaram pelo menos um curso de atualização e $84 \%$ realizaram mais de um curso. Em relação ao último curso de atualização realizado ou em andamento, 20,4\% dos professores o realizaram na área de alfabetização.

Diante da descrição dos participantes da pesquisa, pode-se observar que a maioria dos sujeitos entrevistados possui pelo menos uma pós-graduação e mais do que um curso de atualização na área educacional, revelando que os resultados desta pesquisa indicam a concepção sobre Psicologia Escolar de profissionais que possuem uma formação continuada.

\section{Papel do psicólogo escolar}

Foram feitas as seguintes perguntas aos participantes da pesquisa: "Em sua opinião, qual é o papel do psicólogo na escola?" e "Diante dos problemas escolares, como você acha que o psicólogo deve atuar? O que ele pode fazer?". Dessa forma, somando a opinião dos professores sobre o papel do psicólogo escolar e sobre sua atuação diante dos problemas escolares, obtivemos $44,8 \%$ de respostas relacionadas ao aluno, $21,2 \%$ à família, $11,5 \%$ à escola e $22,5 \%$ a outras funções, incluindo principalmente a concepção dos professores de que o psicólogo possui um conhecimento específico para lidar com os problemas escolares.

Observa-se que, de acordo com os professores entrevistados, a atuação do psicólogo escolar deve estar voltada principalmente para o aluno e sua família (66\%). Este é um dado interessante, pois revela o desconhecimento dos professores acerca de outras atuações possíveis do psicólogo na escola, ou que a forte tendência em localizar no aluno e em sua família as mazelas do fracasso escolar acabe por relegar as outras possibilidades de atuação a um segundo plano. Essas concepções quanto ao papel do psicólogo escolar também foram discutidas na pesquisa de Rossetti e cols. (2004), de modo que eles igualmente verificaram que 
os profissionais entrevistados desconsideraram a atuação do psicólogo na escola a partir de espectros mais amplos.

Frente a isso, levando em consideração a perspectiva crítica, é importante que as múltiplas possibilidades de intervenção do psicólogo na escola sejam reconhecidas pelos professores e por todos os integrantes da escola. Dentre suas possíveis atuações, o psicólogo escolar pode participar na elaboração e reformulação do projeto político-pedagógico; intervir no processo de ensino-aprendizagem a partir de uma concepção histórico-social; trabalhar na formação de educadores através de conteúdos sobre o processo de desenvolvimento e aprendizagem do aluno; intervir em grupos de alunos; e atuar na educação inclusiva, buscando romper com práticas excludentes e promover discussões coletivas sobre o processo de inclusão escolar (CFP, 2013).

No que se refere à atuação do psicólogo escolar frente à família, observou-se que $64,6 \%$ das respostas enfatizaram o acompanhamento familiar, incluindo: apoiar, conversar, orientar e trabalhar com as famílias. Das respostas que relacionam o papel do psicólogo escolar com a própria instituição, $79,1 \%$ consideraram que o papel do psicólogo escolar é ajudar, conversar e trabalhar junto aos professores.

No que se refere a possíveis atuações do psicólogo escolar junto ao aluno, a maior quantidade de respostas $(53,3 \%)$ revelou que, na opinião dos professores, esta atuação deve ocorrer com alunos que possuem problemas (afetivos, cognitivos, comportamentais, emocionais, familiares, psicológicos e de relacionamento) e com crianças com deficiência, incluindo algum tipo de déficit, distúrbio, transtorno ou síndrome. Tal dado permite perceber, no que se refere ao grupo entrevistado, que o psicólogo escolar atuaria predominantemente junto aos alunos com alguma dificuldade.

Entretanto, sabe-se que este modelo curativo e esta prática centrada no indivíduo não conseguem atingir a complexidade das relações inseridas na instituição escolar (Giongo \& Oliveira-Menegotto, 2010). Portanto, o papel da Psicologia Escolar não é restrito à resolução de problemas, devendo, na verdade, haver também um enfoque preventivo (Oliveira \& Marinho-Araújo, 2009; Sant'Ana \& cols., 2009; Valle, 2003).

Além disso, sabe-se que a atuação do psicólogo na escola deve considerar uma dimensão ampliada para todos os envolvidos na educação (Andrada, 2005; Vokoy \& Pedroza, 2005), contemplando intervenções individuais, mas também coletivas (Vebber, 2013) com "os diferentes segmentos da escola, a partir de uma visão crítica sobre as diferentes dimensões (sociais, políticas, econômicas) da realidade que permeiam a ação educativa" (Sant'Ana \& cols., 2009, p.35).

A atuação orientada para o grupo de alunos, não apenas para "alunos problemas", pode permitir que o professor perceba as crianças em seu jeito individual de ser, transpondo os muros da escola para conhecer sobre o aluno mais do que o currículo escolar determina e, dessa forma, melhorar o seu desempenho, envolvendo-se em seus interesses e realidades (Valle, conforme citado por Valle, 2003, p.25)
Este resultado está em consonância com a pesquisa de Miranda e cols. (2007), que também observaram em seu estudo com profissionais de uma escola municipal de Fortaleza (CE), que apesar dos participantes evidenciarem a importância de que haja psicólogos inseridos nas escolas públicas desta cidade, há uma heterogeneidade de expectativas a respeito da atuação do psicólogo escolar, e em sua maioria, os participantes possuem a concepção de que o psicólogo irá utilizar um modelo clínico, centrado nos alunos que apresentam algum problema, tais como, indisciplina e dificuldade de aprendizagem.

Giongo e Oliveira-Menegotto (2010) também verificaram equívocos na concepção de 44 professores de quatro escolas municipais de Novo Hamburgo, situadas na região metropolitana de Porto Alegre (RS), sobre o papel e as possíveis intervenções do psicólogo escolar. Nesse estudo, os autores observaram três concepções dos professores sobre o papel do psicólogo escolar, sendo duas delas, o desconhecimento de sua função e a expectativa de uma atuação clínica, voltada para o diagnóstico e cura de problemas dos alunos, tais como a dificuldade de relacionamento e de aprendizagem (Giongo \& Oliveira-Menegotto, 2010).

Conclui-se, portanto, que o resultado desta pesquisa está em consonância com diversos estudos, uma vez que evidenciam a expectativa de professores acerca de uma atuação clínica em Psicologia Escolar. Frente a isso, é importante discutir o papel dos próprios psicólogos escolares na construção dessa expectativa, pois alguns profissionais da área ainda não romperam com a visão clínica tradicional de atuação marcada pelo início da história da Psicologia Escolar no Brasil (Giongo \& Oliveira-Menegotto, 2010). No próprio município de Vitória (ES), Rossetti e cols. (2004) constataram que a maioria dos psicólogos escolares entrevistados utilizava principalmente abordagens clínicas, corroborando com resultados de pesquisas nacionais.

Sabe-se que essa perspectiva clínica tradicional vem sustentando os processos de culpabilização dos alunos e de sua família pela via da psicologização e patologização dos problemas escolares, que limitadamente são explicados como consequência de dificuldades intelectuais, afetivas, comportamentais, de personalidade ou de falta de apoio familiar (Meira, 2003). Portanto, trata-se de uma concepção considerada insuficiente para abranger a complexidade de relações imersas no processo de escolarização (Giongo \& Oliveira-Menegotto, 2010).

Dentro dessa discussão, Tondin, Dedonatti, e Bonamigo (2010) analisaram as concepções de Psicologia Escolar presentes nos projetos de lei que inserem os psicólogos na rede pública de educação nos municípios de Santa Catarina. Os autores constataram que a legislação contempla uma variedade de concepções teóricas tradicionais e contemporâneas e não contempla a amplitude de atividades que podem ser desenvolvidas pelo psicólogo escolar. Dessa forma, observa-se que a própria legislação não aborda uma concepção crítica da Psicologia Escolar, o que repercute diretamente no trabalho do psicólogo. 
Em suma, ressalta-se que o psicólogo escolar deve buscar substituir o modelo individualizado e curativo de atuação (Giongo \& Oliveira-Menegotto, 2010), de modo a abarcar o aluno como um todo, suas interações e todo o processo escolar. Trata-se, assim, de adotar "uma prática mais sistêmica e institucional, considerando a problemática como algo que está para além do indivíduo" (Giongo \& Oliveira-Menegotto, 2010, p.869).

\section{Considerações Finais}

Os dados obtidos neste estudo permitem observar que na concepção dos professores entrevistados, a atuação do psicólogo escolar é percebida vinculada principalmente ao aluno e à sua família. Essa visão, além de não explorar todas as facetas dos problemas, contribui para o fortalecimento de uma imagem limitada do papel do psicólogo escolar e para o desconhecimento de suas possíveis intervenções.

Em relação a isso, é importante pensar na responsabilidade dos próprios psicólogos na formação de opiniões sobre o seu trabalho, pois muitos ainda possuem concepções clínicas, tradicionais e repletas de estereótipos sobre as queixas escolares (Braga \& Morais, 2007; Cabral \& Sawaya, 2001; Machado \& Souza, 2004). Nesta perspectiva, a compreensão que os professores têm da função e das possíveis atividades a serem desempenhadas pelo psicólogo escolar reproduzem a história da atuação deste profissional em nosso país (Giongo \& Oliveira-Menegotto, 2010).

Os cursos de Psicologia também possuem um papel importante nessa questão, pois alguns estudos indicam que muitos dos problemas referentes à formação do psicólogo escolar no Brasil são derivados de currículos inadequados, ausência de estágios bem supervisionados e falta de preparo acadêmico das faculdades (Novaes, 2001; Rossetti \& cols., 2004).

Diante disso, este estudo aponta para a necessidade de realizações de novas pesquisas que visem elucidar amplamente como a função do psicólogo escolar é compreendida, incluindo a concepção dos alunos, o que é importante "na medida em que pode fornecer indícios para o profissional redimensionar sua prática, voltando suas ações às reais demandas da comunidade em que está inserido, bem como pode subsidiar discussões acerca da formação do psicólogo que atua nessa especialidade" (Sant'Ana \& cols., 2009, p.35).

Além disso, também é relevante investigar a própria atuação de psicólogos na educação básica, objetivando conhecer quais são e como ocorrem, de fato, as intervenções práticas cotidianas do psicólogo escolar e esclarecer suas múltiplas possibilidades. Portanto, espera-se que esta pesquisa possa contribuir na reflexão da prática do psicólogo escolar, de forma a percebê-la em uma perspectiva crítica e contextualizada.

\section{Referências}

Andrada, E. G. C. (2005). Novos paradigmas na prática do psicólogo escolar. Psicologia: Reflexão e Crítica, 18(2), 196-199.

Bardin, L. (2010). Análise de conteúdo. Lisboa: Edições 70.

Barros, C. S. G. (2002). Pontos de Psicologia do Desenvolvimento (12a ed.). São Paulo: Ática.

Braga, S. G. \& Morais, M. L. S. (2007). Queixa escolar: atuação do psicólogo e interfaces com a educação. Psicologia USP, 18(4), 35-51.

Cabral, E. \& Sawaya, S. M. (2001). Concepções e atuação profissional diante das queixas escolares: os psicólogos nos serviços públicos de saúde. Estudos de Psicologia, 6(2), 143-155.

Carvalho, T. O. \& Marinho-Araujo, C. M. (2009). Psicologia Escolar no Brasil e no Maranhão: percursos históricos e tendências atuais. Psicologia Escolar e Educacional, 13(1), 65-73.

Carvalho, T. O. \& Marinho-Araujo, C. M. (2010). Psicologia Escolar e Orientação Profissional: fortalecendo as convergências. Revista Brasileira de Orientação Profissional, 11(2), 219-228. Disponível: http://pepsic.bvsalud.org/pdf/rbop/v11n2/v11n2a07.pdf

Conselho Federal de Psicologia [CFP] (2000). Resolução n. 016/2000 de 20 de dezembro de 2000. Brasília: CFP. Recuperado: 18 abr. 2015. Disponível: http://site.cfp.org.br/wp-content/ uploads/2000/12/resolucao2000_16.pdf

Conselho Federal de Psicologia [CFP] (2007). Resolução $n$. 013/2007 de 14 de setembro de 2007. Brasília: CFP. Recuperado: 06 fev. 2016. Disponível: http://site.cfp.org.br/wp-content/ uploads/2008/08/Resolucao_CFP_nx_013-2007.pdf

Conselho Federal de Psicologia [CFP] (2013). Referências Técnicas para a Atuação de psicólogas (os) na Educação Básica (1a. ed). Brasília.

Conselho Nacional de Saúde (2012). Resolução n. 466 de 12 de dezembro de 2012. Brasília: MS. Recuperado: 18 abr. 2015. Disponível: $\quad$ http://conselho.saude.gov.br/resolucoes/2012/ Reso466.pdf

Giongo, C. \& Oliveira-Menegotto, L. M. (2010). (Des) Enlaces da Psicologia Escolar na rede pública de ensino. Psicologia USP, 21(4), 859-874.

Gonsalves, E. P. (2003). Iniciação à pesquisa científica (3a ed.). Campinas: Alínea.

Machado, A. M. \& Souza, M. P. R. (Orgs.). (2004). Psicologia Escolar: em busca de novos rumos (4a. ed.). São Paulo: Casa do Psicólogo. 
Meira, M. E. M. (2003). Construindo uma concepção crítica de Psicologia Escolar: Contribuições da Pedagogia Histórico-Crítica e da Psicologia Sócio-Histórica. Em M. E. M. Meira \& M. A. Antunes (Orgs.), Psicologia escolar: teorias críticas (pp.13-78). São Paulo: Casa do Psicólogo.

Miranda, L. L., Lima, T. R., Teixeira, P. A. S., Chaves, F. L., \& Barros, J. P. P. (2007). Perspectivas de atuação do psicólogo escolar na rede pública de ensino: um estudo exploratório em uma escola de Fortaleza. Psicologia da Educação, (25), 113-129. Disponível: http://pepsic.bvsalud.org/pdf/psie/n25/v25a07.pdf

Nakamura, M. S., Lima, V. A. A., Tada, I. N. C., \& Junqueira, M. H. R. (2008). Desvendando a queixa escolar: um estudo no serviço de psicologia da Universidade Federal de Rondônia. Psicologia Escolar e Educacional, 12(2), 423-429.

Novaes, M. H. (2001). Visão transdisciplinar na formação do psicólogo escolar. Em S. M. Wechsler (Org.), Psicologia escolar: pesquisa, formação e prática (pp. 127-136). Campinas: Editora Alínea.

Oliveira, C. B. E., \& Marinho-Araújo, C. M. (2009). Psicologia Escolar: cenários atuais. Estudos e Pesquisas em Psicologia, 9(3), 648663. Disponível: http://pepsic.bvsalud.org/pdf/epp/v9n3/v9n3a07. pdf

Patto, M. H. S. (1997). Introdução à Psicologia Escolar (3a. ed.). São Paulo: Casa do Psicólogo.

Piaget, J. \& Inhelder, B. (1994). A Psicologia da criança (13a. ed.). Rio de Janeiro: Bertrand Brasil.

Piletti, N. (2003). Psicologia Educacional (17a. ed.). São Paulo: Ática.

Rossetti, C. B., Silva, C. A., Batista, G. L., Stein, L. A., \& Hulle, L. O. (2004). Panorama da Psicologia Escolar na cidade de Vitória: um estudo exploratório. Paidéia, 14(28), 191-195.
Sant'Ana, I. M., Euzébios Filho, A., Lacerda Junior, F., \& Guzzo, R. S. L. (2009). Psicólogo e escola: a compreensão de estudantes do ensino fundamental sobre esta relação. Psicologia Escolar e Educacional, 13(1), 29-36.

Souza, M. P. R. (2009). Psicologia Escolar e Educacional em busca de novas perspectivas. Psicologia Escolar e Educacional, 13(1), 179-182.

Tondin, C. F., Dedonatti, D., \& Bonamigo, I. S. (2010). Psicologia Escolar na rede pública de educação dos municípios de Santa Catarina. Psicologia Escolar e Educacional, 14(1), 65-72.

Valle, L. E. L. R. (2003). Psicologia Escolar: um duplo desafio. Psicologia: Ciência e Profissão, 23(1), 22-29.

Vebber, F. C. (2013). Psicologia Escolar: relato de uma experiência no ensino fundamental. Revista Psicologia: Teoria e Prática, 15(1), 194207. Disponível: http://www.redalyc.org/pdf/1938/193826310006. pdf

Vokoy, T. \& Pedroza, R. L. S. (2005). Psicologia Escolar em educação infantil: reflexões de uma atuação. Psicologia Escolar e Educacional, 9(1), 95-104.

Wechsler, S. M. (1989). Panorama nacional da formação e atuação do psicólogo escolar. Psicologia: Ciência e Profissão, 9(3), 26-30.

Wechsler, S. M. (Org.). (2001). Psicologia escolar: pesquisa, formação e prática. (2a. ed.). Campinas: Alínea.
Recebido em: 06/07/2015

Reformulado em: 16/02/2016

Aprovado em: 18/05/2016

\section{Sobre as autoras}

Caroline Benezath Rodrigues Bastos (carol_benezath@hotmail.com)

Psicóloga, Mestre em Psicologia e Doutoranda em Psicologia na Universidade Federal do Espírito Santo.

Simone Chabudee Pylro (simone.chabudee@gmail.com)

Psicóloga, Mestre e Doutora em Psicologia e docente na Universidade Vila Velha. 